\title{
The Meaning of Chronic Pain: A PHENOMENOLOGICAL ANALYSIS
}

\begin{abstract}
Chronic pain sufferers are frequently misunderstood and stigmatised. The aim of this investigation was to provide a description of the life-world of people with chronic low back pain, using the phenomenological method. Themes which emerged were that the persistent nature of chronic pain makes it particularly difficult to endure, arousing a profound fear of the future. Chronic pain causes a disruption in the relationship between the person and the body. The person is forced to function within the constraints of

WADE BL, BSc Physiotherapy (W its), Hons BSc Psychology (Unisa), MSc Psychology (Unisa) ${ }^{1}$; Shantall HM, D Litt et Phil (Unisa) ${ }^{1}$

${ }^{1}$ Department of Psychology, University of South Africa pain and to find ways of coping. Sufferers are unable to fulfil social roles as expected and are forced to revise their goals and activities to accommodate the pain. The distress of their experience is mediated by the ability to make sense of their condition, finding meaning in the pain itself.

This study highlights the value of the phenomenological method in health psychology. Recommendations are made which may be of benefit to people with chronic pain and their families. The multidimensional nature of chronic pain is highlighted and implications for various professionals who work with chronic pain patients are discussed.
\end{abstract}

KEY WORDS: CHRONIC LOW BACK PAIN; COPING; MEANING; PHENOMENOLOGY; HEALTH PSYCHOLOGY

This research w as conducted in partial fulfilment of the requirements for a Master of Science degree in psychology at Unisa.

\section{INTRODUCTION}

Chronic low back pain is far more than a series of nerve impulses which produce an unpleasant physical sensation. Although acute and chronic pain may arise originally from similar tissue damage or disease, chronic pain is not simply acute pain which has become unusually long standing. Chronic pain may become a complex phenomenon over time, which impacts on a persons life, imposing widespread changes in relationships, goals and dreams, incorporating biological, psychological and social aspects. Whereas acute pain subsides with healing, chronic pain does not. Therefore, chronic pain appears to have no relation to demonstrable tissue damage or disease and seems to take on a life of its own. Such changes are known to extend even to the neurophysiology

CORRESPONDENCE TO: B L Wade

PO Box 131275

Northmead

I511

Tel: (011) 967-2200 of the body. Recent findings indicate that there is a relationship between chronic pain and the immune system. As an illustration, recent work has demonstrated that thymulin, a thymic hormone known to activate the immune system, can produce hypersensitivity and inflammation in the body. This hormone has also been shown to increase reactivity in certain receptors in the peripheral nervous system. It can also increase reactivity in the dorsal horn which can be reversed by morphine. It was concluded that chronic pain is a reflection of the cross talk between the nervous, immune and endocrine systems. This reflection of homeostatic imbalance does not depend upon specific pathways or cerebral centres. "Like other limbic functions it can emerge at the conscious level in humans in the form of an unpleasant experience with psychological and behavioural changes" (Jabbur and Saade 1999).

There is evidence that the nervous system is more dynamic and malleable than has previously been supposed. This is known as plasticity. An important concept in neuronal plasticity is that of wind up. If a series of stimuli are applied in rapid succession to a nerve, the size of the impulse generated will increase. This has important clinical implications. If pain is present for a long time, it will become increasingly more painful and may lead to changes in the nociceptive pathway (Hawthorne and Redmond 1998). Changes in central pain mechanisms may play an important role in the generation and maintenance of chronic pain. What happens in these circumstances is that the central processing of information from peripheral nerves is altered so that fibres which are not normally nociceptive, generate impulses which are interpreted as pain. Injury to a nerve (as in compression due to a prolapsed disc in the spine, inflammation due to arthritis or compromise to the nerve's blood supply) results in the generation of abnormal impulses. The molecular constituents of the nerve dam up at the sight of the injury making the nerve hyper- excitable. Such damaged nerves are able to generate their own pattern of firing independent of the sensory apparatus and are called "ectopic pacemaker sites." Cross excitation with 
other neurones occurs, so that other sensations, such as light touch, are interpreted as pain. This is known as allodynia. This sensitivity spreads to adjacent dermatomes, so that pain becomes increasingly widespread (Shipton 1993; Hawthorn and Redmond 1998).

Psychological factors influence the experience of pain. It is postulated that when a person is ill or depressed the background level of some neuropeptides may be lowered, resulting in increased susceptibility to pain. Kerns et al (1993) suggest that learned inability to express negative emotions such as anger may suppress the effect of opiods which are produced by the body to moderate the experience of pain. This may lead to reduced pain tolerance. Laughter and joy may have the converse effect (Charman 1989).

These findings indicate that acute and chronic pain differ in important ways. It is sobering to note that, although some patients learn to live with chronic pain in more appropriate ways, they seldom return to the pre-pain state of function. Linton (1987) noted that, even after treatment, the final level of functioning of patients with chronic back pain was still clearly below that of their peers without pain. Although some patients may enjoy periods of remission during the course of the condition, most people with chronic health problems are confronted with the possibility of incapacitation, rising costs, long-term medical management, and the constant threat of deterioration (Gregg et al 1989). This may have an impact on a person's self concept, behaviour and well-being as well as on the family and society. It is essential for the physiotherapist to understand the impact of chronic pain on the life-world of the patient in order to offer optimal rehabilitation and care.

"Second to the common cold, back pain is the most prevalent affliction of man" (Hawthorn and Redmond 1998). $80 \%$ of persons are likely to be affected by back pain at sometime in their lives. Bardin (2002) cites Taimela et al (1997) suggesting that $35 \%$ of those with low back pain develop a chronic problem In most cases, back pain resolves spontaneously. Although this seems to imply that many patients will not need any active intervention, this conclusion must be tempered by the fact that the earlier the intervention is received, the better the prognosis. Once back pain has been present for six weeks, it is likely to become chronic. Once it has been there for six months, there is only a $50 \%$ chance of return to work (Hawthorn and Redmond 1998).

Chronic pain can span an enormous spectrum of intensity from mild discomfort to agony. It is puzzling that responses to pain, even within an individual, may vary at different times and under different circumstances. Pain may take on a variety of meanings which greatly influence the way in which it is tolerated and perceived (Autton 1986). The manner in which pain is interpreted influences the intensity of the pain perceived as well as the outcome of treatment interventions (Eales 1999). The boundaries between the sensory and emotional dimensions of pain are not rigid, but fluid, functioning like parts of a whole. Reducing either the physical component or emotional component, has the capacity to reduce the whole (Fernandez et al 1999).

The ability to tolerate pain is subject to wide variation, as illustrated by the way individuals are often able to tolerate pain during culturally bound rituals. It may appear that differences in pain experience between different individuals are due to different pain thresholds. However, there is considerable evidence that the threshold at which pain is perceived is remarkably constant across ethnic groups (Bishop 1994). Melzack and Wall (1982) conclude that differences in pain tolerance amongst members of various cultural groups are a reflection of different ethnic attitudes towards pain.

It seems that the meaning and emotional significance attributed to pain may have changed, particularly in Western cultures (Illich 1976). Menges (1984) states that "the Western world has become increasingly sensitive to pain, particularly in the last century." With advances in Western medicine, people have become less tolerant of pain and have great expectations of altering it. Consequently, unrealistic expectations regarding the potential for healing and cure have emerged. Thus contemporary
Western society does not regard pain as acceptable and it is viewed increasingly as an abnormal and unnatural part of life (Hilbert 1984). Waddell (1991) argues that "chronic disability due to simple backache is a relatively recent peculiarly Western epidemic."

Cultural differences of this kind indicate that the meaning of experience to a particular person, including the meaning of illness and pain, will depend in part upon the meaning assigned by the person's social group. Cultural norms determine whether the sick person will be considered acceptable or disgusting, whether they are to be pitied or censured, or whether he or she should be isolated or not. Cultural definitions of illness may be a source of suffering for the sick person. Such definitions frequently involve a value judgment. Toombs (1992) observes that the suffering which accompanies disability is not solely the result of loss of function, but includes the recognition by the handicapped person of a devaluation in their status, which reflects cultural values. Therefore, the degree of suffering and meaning of pain are linked.

There appears to be a widespread perception amongst chronic pain sufferers that no one understands chronic pain like another sufferer. Interaction with the health-care system on the part of patients with chronic pain appears frequently to be unsatisfactory (Price 1996). Miscommunication between patients and medical practitioners, appears to be a real problem. $96 \%$ of medical practitioners in urban areas and $83 \%$ of medical practitioners in rural areas in South Africa who took part in a study conducted by Papaikonomou (1991) "believe that there is a communication gap between medical practitioners and their patients, where information is not understood or is understood in a different way, by the medical practitioners and patient." Toombs (1992) examined the way in which meaning is assigned to symptoms from the perspective of patients and their physicians, drawing from her own experience as a multiple sclerosis patient, as well as phenomenology. She argues that the biomedical model is an inadequate model for medical care. She explains that, from the 
phenomenological point of view, illness is understood from different perspectives by patients and medical practitioners. The patient experiences illness in its immediacy as the disruption of their life world. This experience is a pre-theoretical one. In contrast, the physician focuses on the disease process itself. In this sense illness is regarded as a dysfunction in the biological body (rather than a disruption of the lived body.) The patient's subjective report is re-interpreted in terms of the physician's understanding of disease processes. This involves an abstraction from the patient's pre-reflective experience to a scientific account of the causal structure of such experiencing. Although it may appear that the patient and physician are talking about the same reality, from a phenomenological viewpoint these realities are distinct. She states that therapy is less likely to be successful if the meaning of illness to the patient is not taken into account. Such meaning is not apparent from clinical data alone, but the lived experience represents the reality of the patient's illness. Toombs (1992) argues that distortions in communication can only be remedied once the differences on which they are based are understood. Such differences with respect to chronic pain in particular have not been explored. However, provision of a phenomenological description of pain from the patient's perspective could provide the basis on which communication between patients and members of the medical profession may be clarified.

\section{Aim and Rationale of this Study}

The present study differs fundamentally from conventional quantitative studies in terms of its research objective, namely, to provide a holistic description of the meaning of chronic pain. Bardin (2002) has emphasized the importance of evaluating the impact of chronic low back pain on the patient's life in order to develop relevant treatment outcome measures, especially quality of life measures, because objective outcome measures related to the biological component bear only a weak relationship to the patient's behaviour and symptoms. Prospectively planned outcomes need to be defined. This implies that explo- ratory studies have an important role in assessing the impact of chronic pain on the life world of the individual. Furthermore, the suggestion has been made that successful management may lie in changing the meaning of chronic pain. "Personal constructs of this kind are dynamic, ever-changing reflections of the person's adjustment to the environment" (Large and Strong 1997).

The phenomenological method used in this research is a qualitative approach which provides a means by which the way reality as experienced by a particular person can be explored in a rigorous fashion (Cleaver and Pallourious 1994; Toombs 1992). The phenomenological method has been chosen as the means by which to study the meaning of chronic pain because chronic pain is not "something," which a person "has." It is an experience with which a person lives and phenomenology provides a means of exploring experience as it is lived. The essential features of events and occurrences as experienced by the individual are described, in order to determine the essential character of the experienced phenomenon. This enables the researcher to arrive at an "extended description" of the core features of the phenomenon of interest (Toombs 1992; Giorgi 1983; 1992). In this way, the essence of experience may be disclosed (Giorgi 1997).

\section{Sampling and Selection of Research Participants}

Three participants, all females, who had experienced unrelieved, continuous chronic low back pain for periods ranging from eight to thirty nine years were approached to take part in this study. They were people who have no option but to cope with pain. Subject selection was purposive. Subjects were included on the basis of certain criteria, namely: they experience chronic pain, that is suffer from the condition, so as to be in a position to describe it; they expressed willingness to discuss the matter freely and openly; they were capable of providing rich descriptions of their experience; they were naive with regard to psychology to avoid the possibility of their accounts being influenced by prior theories or knowledge; subjects were willing to commit sufficient time to the interviews (Kruger 1979). Permission was obtained to tape record interviews and to publish results. Participants were assured that their names would be changed in the report, to preserve their anonymity.

\section{DATA COLLECTION}

Data were obtained during open-ended unstructured interviews. Unstructured interviews were used in this investigation to gather the data because the phenomenological method requires that the researcher should put aside all preconceptions regarding the phenomenon of interest, so as to observe it as it presents itself (Kruger, 1979). Imposing a structure on the interviews would interfere with this process. For the same reason, no pilot study was conducted, so as not to bias the researcher's thinking prior to commencing with the study.

Each participant was asked the same initial question, namely "Please describe as fully as possible your experience of chronic pain." Participants were left free to answer this question as they chose. Leading questions, suggestive of particular answers were not asked, although the researcher did ask for clarification or further elaboration by the subject (Barrell et al, 1987). The number and duration of the interviews were selfdetermining, continuing until the researcher felt that a saturation point had been reached and that the participant had explicated her experience fully. Interviews were tape recorded and transcribed.

\section{The Explication of the Data}

The aim of the phenomenologist is to understand a phenomenon, as fully as possible, as it presents itself. The method outlined by Kruger (1979) was selected for the analysis of the protocols. This included the following steps:

The first author bracketed all pre conceptions regarding chronic pain. With its emphasis on a radical reflection upon lived experience, the phenomenological approach requires a commitment to setting aside or bracketing prior theoretical or common sense presuppositions in order to focus on the phenomenon of interest as it presents itself. This involves a radical disengagement or 
distancing from habitual ways of interpreting the world (Toombs 1992).

The first author immersed herself in the data, reading and re-reading the transcripts and listening to the tapes in order to gain a holistic view of the data.

Once a holistic intuitive grasp of the data had been gained, the transcripts of each participant were broken down into natural meaning units. Each natural meaning unit is a statement made by the subject which is self definable, and self delimiting in expressing an aspect of the subject's experience. These meaning units were appraised by the second author.

Thereafter, those meaning units which were repeated were eliminated in order to construct a first order profile. This in turn was converted into a constituent profile "which is a condensed summary of the original data in the words of the researcher containing the essence of what the subject expressed" (Shantall 1996). This process was repeated on the constituent profile to yield a second order profile. In the next stage of the analysis, statements with similar though not identical meaning were gathered into categories which were arranged in a hierarchical sequence, describing the characteristics of chronic pain.

The themes arising from this process were used to write an "extended description," from which the researcher could gain an overall view of the experience of chronic pain, capturing the core qualities of the phenomenon.

\section{RELIABILITY AND VALIDITY}

The criteria by which reliability and validity of a study such as this are judged should be appropriate to qualitative research, which has a different epistomological foundation to quantitative methodology (Osborn and Smith, 1998). Such criteria have been detailed by several authors (Stiles, 1993; Osborn and Smith, 1998). The reliability and validity of this study are detailed elsewhere (Wade, 2000).

\section{RESULTS}

It is beyond the scope of an article such as this to give a full transcript of each participant's experience. Therefore only the main themes, as well as the extended description, based on the interpretation of the protocols are presented.

\section{Categories Disclosing the Characteristics of Chronic Pain}

Chronic pain is persistent, giving it a quality that is particularly difficult to endure.

Participants related that chronic pain is a noxious stimulus which is there for the rest of one's lifetime and that it is the relentless nature of the pain that makes it particularly difficult to endure. They felt forced to cope or escape. The realisation that chronic pain will not resolve has forced them to regard death as the only release from pain. Molly admitted: I have at times, when the pain was really bad, actually prayed that God would take my life.

Participants were able to understand why some commit suicide, viewing their peers who choose this option with trepidation, knowing that for some, chronic pain is so intolerable and inescapable, that this option makes sense. Controlling the level of pain which has to be endured is critical in enabling sufferers to cope. Joyce explained:

Well, if you are suicidal with pain like that, and they tell you there's nothing wrong, nobody can help you, that there's no way out of the pain, you will find a way. You will take a box of painkillers and just end it all. I really feel that.

Participants indicated that the person with chronic pain does not realise initially that the pain is permanent. Expectations are such that the pain "should get better". In addition, the sufferer is often confronted with a problem that no visible signs can be found to validate one's complaint. The difficulties encountered in proving the reality of one's pain makes one vulnerable to judgement by others and may have long term consequences. Molly's recovery from surgery did not fit a prescribed pattern. She was particularly upset to find that she was blamed for the failure of the operation, although she had followed all the instructions to the letter. As a result of her poor recovery she was stigmatised and told that "she wasn't putting her all into getting better." She has suffered from permanent iatrogenic hip pain as a result of this incident. Participants reported being labelled "mad or bad", creating a fear that one has an even worse problem, namely a problem "in the mind." This problem was amply illustrated by Joyce, whose doctor refused to acknowledge the validity of her complaint, causing her to lose a disability claim: You've got no power and you've got no proof... What do you do? He says to you "You've got no pain" And you sit and look at him. Now you think you've become a hypochondriac. But, you realise "I have got pain!" "No, you haven't - there's nothing showing up on this X-ray. Lady, do you want to be sick or do you want to be better?" "No, no I want to be better." "Well then, there's nothing wrong with you!"

In contrast to this, Molly related that she desperately wanted to hear that she was a hypochondriac. She desperately wanted to escape from the pain. The doctors acknowledged that she had a genuine back problem and told her not to come back, because there was nothing they could do for her. She explained her response as follows: I thought it would be so much easier if I had a mental problem, because that was something I could work on...But if it was a physical problem, then the doctors were right and there was nothing I could do.

\section{Pain Takes Over Your Life}

Participants compared the past and the present, regarding the past as the way they should be or wished to be, mourning their loss. They felt forced to learn a whole new way of life, in which pain is the master. Participants described how chronic pain leaves one feeling powerless and victimized. Chronic pain seems to take on a life and character of its own. The affected body seems "separate" from the person and may be personified. Molly lamented: My back had taken over my life.

Participants related that the body no longer obeys spontaneously and has to be placed under conscious control. The painful body seems to imprison one and too much effort to escape may be severely punished. One is forced to function within pain's constraints, which is distressing. Molly described this tension as follows: I think this is what 
makes pain so difficult - there's absolutely nothing wrong with your brain. Your brain is still active, your brain still wants to do things, your brain still wants your body to do things. But your body, because of the pain, just cannot work with your brain. And it is very frustrating. Very, very frustrating. You've actually got a little war going on inside you.

\section{Chronic Pain Causes Interpersonal Difficulties}

Participants say that that admitting to pain constantly is socially unacceptable. They find themselves in a dilemma in social relationships between genuine openness and fear of rejection. However, one cannot relate to others free of pain. Pain affects social roles. Sufferers have to find a balance between the restrictions imposed by pain, and the demands of everyday life. One has to learn to be vulnerable, and learn to receive, and still enjoy life, in spite of pain. Gerda explained how this dilemma may be overcome: The thing is you have to come to a point basically, where you are prepared to be vulnerable. Vulnerability is something that, if you want to build a relationship, is absolutely vital, because you can't build a relationship without it.

Participants explained that, not only is the sufferer vulnerable to judgement by health professionals, but also by significant others. Chronic pain does not make sense to relatives and friends who believe it "should" be curable. Careless comments are often hurtful. Gerda reflected on this issue:

I had to learn to accept myself, regardless of what everybody thinks or says. That doesn't mean to say I don't take notice of what they think. You know, one can think you are cut off from people and that you don't allow people to affect you by their thoughts and their mannerisms, and by their approach to you, but I don't think there is anyone of us who is able to withstand what others around us say and do. We all think about it.

However, precisely because the pain does not resolve, sufferers have a need for ongoing social support. Molly acknowledges that it is difficult to admit that she cannot cope by asking someone to do something for her. She had to learn to ask for help, which is difficult because one is scared of rejection. Even if you do ask for help you feel you are a nuisance. However, she has learnt from experience that there are friends around her who are in fact only too willing to help. Nevertheless, she tries by all means to hide her pain whenever possible: If somebody asks me how I am, I will never say "I'm in pain today." Never!...I just feel I am a weakened person if I admit to pain all the time.

Molly feels that chronic pain has destroyed her confidence in social interactions: "I must be a pain to be around." Social gatherings, which were once a source of pleasure, have become a source of stress because "you don't want to dampen the day."

Support from health professionals, family or friends, enabled participants to view the social world as a source of comfort. When support is lacking, the social world may be regarded as threatening, causing the sufferer to retreat further and further from it despite a desperate need to be understood, as in the case of Joyce, who hides her pain from the family: I can't say anything. Most confusing. Most upsetting. I actually am very unhappy that they don't know because I put on this huge act. "Oh come inside, sit down, how are you? How about tea?" Nobody ever helps me. I make the tea, put biscuits on the plate, or cut the cake, carry this massive tray, and everybody sits and chats, nobody knows and they won't know because I don't want them to know.

Participants indicated that they are sensitive about divulging their experience, knowing that the compassion of non-pain sufferers is limited. Joyce commented: People don't click with someone who is always complaining.

\section{One is Alone}

Although chronic pain impacts one's relationships, it is an experience in which one is profoundly alone. No one can take one's place and participants said they realise that no one else knows what you are going through. People with chronic pain may find solace in religion. For Gerda, faith is the answer to the problem. She sees God as one who is able to share her experience, One who can look at the full extent of what she is going through without having to turn His face away. She can turn to Him at any time. In that, she finds comfort. She emphasised the importance of her faith continually, stating that psychology is only of limited value in dealing with chronic pain: You're totally on your own. Only a person that has gone through pain will really understand, and even then your pain differs, and your understanding differs. I have learnt to say I have empathy, I have an appreciation of (another's pain), but not to say that I totally understand. No one will totally understand what another is experiencing from the point of view that they're not in your situation. They do not have your psyche. They do not have your emotions. They do not have your body. They are totally unable to have a deep comprehensive understanding. To say you have a total understanding is a no, no. It's just not there, because we are all so different.

Molly was upset that there is so little help available to assist patients to deal with pain. She was told by the doctor that she was beyond help and must learn to live with her pain. She felt betrayed and abandoned: The neurosurgeons and orthopaedic surgeons all sit back and say "this has happened to you, now you've got to learn to live with it." They don't realise that 24 hours in the day is a long time when you've got constant pain.

\section{Chronic Pain Creates a Bleak Future}

Participants in this study had all experienced a deterioration in their condition over the years. Medical interventions had failed, destroying their hope that a cure could be found. They longed to be rid of the pain permanently and acknowledged that the course of chronic pain is uncertain and one's current experience of pain, especially worsening pain, provokes a profound fear of the future, as described by Joyce: It is a bleak future. When you sit and feel sorry for yourself. It is a hell of a bleak future...It is just one terrible thing to live with. I just wish somebody could come and take it away! But they are not going to take it away. I have realised lately that this is a permanent thing and I do not know what to do about it... If I am 
going to be in bed constantly and unable to do anything, people are going to switch off from me and just push off...So maybe I'm scared of rejection...You know that the thought of living with pain for another 20 years is not a good thing. It is scary. It is very, very scary.

Gerda seemed to sum up their experience when she stated I think the one thing we all fear is helplessness. This fear seems to be mediated by the willingness of others to provide support. Most of all, the participants feared being abandoned and losing their personal worth. I like people to want me for who I am. Not for what I need from them. (Joyce)

These fears are so terrifying that participants said they prefer not to look at the future. It is too much to bear all at once. Efforts are made to live one day at a time, focusing on the good things they have now. They reported a greater appreciation of what they have.

Participants emphasised that it is vital to retain hope, because losing hope may lead to one being overwhelmed by pain and even to suicide. These participants expressed a belief in eternal life, which they felt gave them hope. They stressed the importance of knowing that the pain will eventually end, emphasising that it is the persistent nature of chronic pain that sets it apart, making it particularly hard to bear. Molly was very upset about two members of a support group who lost hope and committed suicide. She explained this as follows: Some people in the group lived for now. They didn't have an idea of eternity, that when this life comes to an end there is another life. The pain became all engulfing because they had nothing left. They had absolutely nothing. All they had to look forward to was daily pain...

\section{Coping with Chronic Pain}

Participants recognised that chronic pain has forced them into a corner where one either has to escape from a life of pain, or one has to cope. Accepting that chronic pain is permanent was the first step in learning to cope. Prior to this, they had engaged in a search for relief and cure, which eluded them. Molly explained: At first I just fought it all the time thinking that I wanted it cured.
Totally cured. And I came to the realization that "Molly, no matter what you do, it is done. It cannot be cured. And you've now got to look for ways to help yourself deal with it more...

But it is very hard in the beginning when you've got constant pain. You don't actually realize that this is going to go on and on and on. It takes a long while for you to start realizing that there isn't an op out there, there isn't a machine out there, there isn't anything out there that can help you.

Participants who had found practitioners who are willing to support and advise them maintained a positive attitude towards the medical profession. Failure to do so resulted in the patient turning away from the profession to a greater or lesser extent, expressing anger at its failure to support and assist them.

Participants emphasised the importance of reducing the level of pain by means of medication, exercise, alternative medicine or physiotherapy. The physiotherapist was perceived as the one person who truly understood and validated the experience of these participants. Participants had worked out ways of decreasing the level of pain, including sensible use of medication. However they expressed a prominent fear of addiction. Gerda highlighted the importance of education and knowledge and of the mind in dealing with pain: More needs to be done for the patient to help you understand why things are happening to your body, then you can cope with it. Molly emphasised the importance of breaking the chain of unbroken pain. She was admitted to hospital periodically and given strong medication to provide a temporary respite from pain: Having had that break enables you to cope... when you just see this as a long road ahead, that you've got this pain for another 50 years, you think to yourself "I just can't cope." You do panic. That is what is frightening.

The relief provided by physiotherapy, however temporary was an important factor in enabling participants to cope.

Coping with chronic pain is an ongoing battle: You have to fight it daily. It is not something that you have fought and it's over with... The day you stop and think "the pain has got the better of me.
I am just going to do nothing," the pain has won. At times participants fight the pain. At times they found it best to rest or curtail activities, adapting to the pain. Gerda stressed the importance of listening to the body: I'm having to learn to say "no." I am not a person that can easily say no. I've got to listen to my body's needs...

Hobbies and interests provided an invaluable respite from pain for these participants. Gerda has developed a keen interest in photography, Molly enjoys arts and crafts and Joyce is studying: Pain makes you sorry for yourself, which is a bad thing. You get depressed, which is bad. So you are totally self-centred when you are in pain. So you have got to get your mind off yourself, and on to something else.

Participants make effective use of "self-talk" to control pain. Another alternative is to distance oneself from pain. Joyce achieves this by using humour. Gerda is able to turn to her spiritual life.

\section{Finding Meaning in Suffering}

Participants found themselves engaged in a struggle to find meaning in their pain. Each one had questioned why it happened. In the absence of any medical explanation, they were forced to find value in the pain itself, seeking an explanation that transcends the physical realm. They needed to find purpose in the new way of life it imposes. Gerda stressed that one needs to find a purpose. If one doesn't find a purpose, or cannot see a purpose in one's life, then you're going to get lost. You're not going to cope.

The distress of chronic pain seemed to be mediated by the ability to find personal meaning in the situation. Sufferers were able to cope when such meaning could be found. Chronic pain was viewed as a stimulus for personal growth. Importantly, chronic pain was viewed as increasing the qualities of compassion, sensitivity, and wisdom. Participants expressed satisfaction in their ability to cope. They felt that they are better equipped to assist others and were less intimidated by suffering: The pain has actually given me an assurance that I can understand people because I have been through it. I have travelled 
that road. (Molly)

They wanted to help others to deal with pain. Joyce was considering visiting hospitals to support others, something which she started to do at the close of the research.

Participants described how the realisation that chronic pain is permanent has forced them to think about the course of life, revising their goals and priorities to accommodate the changes imposed by pain. The heart of the struggle to cope seemed to lie in the sufferer's ability to lead a valued life in spite of the presence of pain. Molly reflected on this process as follows: It has created different opportunities. Before I would not have had the same empathy with somebody with pain as I have now. I have learned, as I have said, that I can go and visit people who are sick, and it doesn't bother me. Before, it would have got to me. Work took up my time and I was not able to do a lot of things. So my life has changed. It's like two different lives in a lifetime. It is like the life before pain and the life after pain. They are very different. Very different. But I can say now that I am content with life, and the things I am able to do now. At first I was not. I really battled. I battled tremendously. But as I got more into it, and more involved, I realised that it was just as rewarding, as what I was doing before, if not more so. I can do something else now. It does not mean that everything was taken away from me. My life is different, but I'm still useful.

\section{The Extended Description}

Based on these findings, the first author was able to write the following description, disclosing the core features of the experience of chronic pain:

Chronic pain is an ongoing noxious physical stimulus, which by its chronic nature imposes a form of distress which extends beyond the physical pain itself. Sufferers feel alienated from the body which no longer functions as it used to and this is experienced as loss. The person feels isolated and trapped within the painful body and is forced to function within its constraints. This causes a shift in social, occupational and family roles, since the sufferer is unable to interact free of pain.
The relentless nature of the problem generates an ongoing need for support, yet the sufferer is isolated in a private experience which makes no sense to outsiders, placing the person in a dilemma between revealing one's distress and the fear of rejection or stigmatization. These contradictory demands for support and discretion are experienced as stressful. The course of chronic pain is unpredictable and does not allow closure. The persistent nature of the pain, coupled with variations in intensity, provoke a profound fear of the future, especially the fear that one will become dependent on others and thereby suffer a loss of personal worth. Sufferers face the threat that ultimately they will be overwhelmed by pain and unable to cope.

Sufferers are forced into a situation where it is imperative to gain a measure of control over the pain, or find some means of escape. Anxiety is reduced if the person is able to control the intensity of the pain or find some means of distancing oneself from it. The distress of chronic pain is mediated by the sufferer's ability to find a personal meaning in the experience itself, in the ability to re-interpret its impact so as to be able to live a valued life in spite of the presence of pain.

\section{DISCUSSION AND RECOMMENDATIONS The Value of Phenomenology in Health Psychology}

The primary focus of this research was to provide a description of the experience of chronic pain from the position of sufferers themselves. Smith (1996) highlights the value of phenomenology in health psychology. Using the phenomenological approach it was possible to access the perspective of sufferers themselves and to focus on what is involved in coping in a way which complements existing studies. Chronic pain is experienced as a disruption of the lived body which impacts the life-world of the person. Phenomenology permits access to the lived experience of the phenomenon. People think about their bodies and assign meaning to their experiences, particularly in the absence of plausible medical explanations for their condition (Smith 1996). Current literature has been criticised for neglecting the lived body in the search for meanings related to chronic pain (Osborn and Smith 1998).

Phenomenology provides a means by which discrepancies in the understanding of illness between individuals can be revealed. Toombs (1992) suggests that there is a tendency towards miscommunication between patients and medical practitioners, because illness is experienced by the patient in its immediacy as a disruption of the lived body, but that the understanding of physicians is an abstraction, focusing on the disease processes in the biological body. She emphasises that these realities are distinct and that this is frequently a source of misunderstanding between patients and their doctors. Phenomenological studies such as this one, provide a basis on which the source of such confusion can be clarified.

The themes which emerged in this study reveal the struggles that patients live through in their pain careers, suggesting where patients' needs lie and where interventions could be focused. The investigation showed that people with chronic pain strive to understand the nature of chronic pain, to assign meaning to their experience and to acquire coping strategies. The study emphasises the multidimensional nature of chronic pain, which implies that a team approach to its management is required. It also reveals the implications for various role players involved with the sufferer.

\section{Implications for the Medical Profession Medical Practitioners:}

Participants' accounts emphasise the inadequate and often punitive nature of the application of a purely biomedical model to chronic pain. This model is unable to supply either an explanation or cure and sufferers are frequently stigmatized as a result. This implies that many medical practitioners need to be equipped to offer support and counselling to patients. Focusing on the credibility of the patient's complaint strengthens the therapeutic alliance, but failure to do so prompts frustration and anger, deepening the patient's distress. When doctors were able to support and listen to participants, this provided a valued form of therapy in itself. 
Chronic pain can become unbearable, yet patients are reluctant to use medication. There is a prominent fear of addiction. The literature indicates that this is rare, since patients who take analgesics purely for pain relief have been shown not to develop the rapid physical tolerance that is often a sign of addiction. Indeed, unnecessary pain has been described as a "tragedy" (Melzack 1990). It seems that more can be done by doctors in terms of educating patients about the correct and safe use of medication and alternative therapies. It is important to note that the intensity of pain seems to have a profound impact on the person's perception of their ability to cope and therefore it is imperative to assist the patient to reduce the level of pain that must be endured.

The authority vested in the medical profession as well as the confidence held in diagnostic tests in terms of compensation, treatment, disability payouts and litigation seems to warrant further careful investigation. Participants expressed distress when their pain was initially denied, based on diagnostic tests, only to be confirmed later, when it was too late to reverse legal and medical decisions regarding their condition. One participant was not compensated financially, because her complaint was not validated until it was too late. Another participant has endured persistent, iatrogenic hip pain because her complaints were ignored. Such decisions may have long term implications for the patient, which influences the effect of chronic pain on his or her life. The negative experiences of these participants lend support for further research into the development of more comprehensive approaches to the management and evaluation of people with chronic low back pain, suggesting that the biomedical model is inadequate when applied to patients with chronic pain (Walker et al 1999; Seers and Friedli, 1996).

\section{Physiotherapists:}

Physiotherapists are often doubtful as to whether it is ethical to continue to treat patients who do not recover for long periods. Treatment outcomes are frequently assessed by methods such as clinical judgement, return to work and test results. However, there has been a change in emphasis recently and the trend is towards taking the patient's perception of what is helpful into account when evaluating treatment outcomes. One of the major objectives of medical care is to improve the patient's quality of life (Eales et al 2000). Participants in this study emphasised that the relief of pain, even for brief periods is beneficial and enhances coping. They described that it is the unbroken nature of chronic pain that makes it so difficult to endure. Therefore, the answer as to whether patients with long term low back pain should continue to receive pain-relieving treatment is an unequivocal "yes." This finding underscores the importance of taking patient's assessment of pain, function and quality of life into account when assessing treatment outcomes, as emphasised by Bardin (2002).

It was note-worthy that participants viewed their physiotherapists as the person who understood their pain best and as the person to whom they were able to disclose their experience. This implies that the physiotherapists provided both physical relief and psychological support and that the value of listening to the person should not be underestimated.

Participants emphasise that they have learnt to cope and could teach others. They indicate that education with regard to the factors and mechanisms which exacerbate pain is valuable in learning to adjust one's lifestyle. Physiotherapists are well equipped to provide such explanations. Discussion groups or back schools could be put to good use to achieve this purpose.

\section{Occupational Therapists:}

Participants used a combination of coping strategies, fighting the pain at some times and adjusting their goals and activities to accommodate the pain at other times. This study highlights the value of a combination of active coping and accomodative coping. Participants did not give up but learnt to find a balance between the constraints imposed by pain and the need to engage in meaningful activities so as to retain a sense of worth. Previous research has indicated that patients who had at least one active interest were better able to cope with chronic pain (Walker et al 1990)

This suggests that occupational therapists could play an important role in assisting sufferers to establish suitable, enjoyable hobbies and interests. This is particularly important because participants indicated that they are able to gain control over the pain by escaping into their interests or distancing themselves from pain. Psychologists and occupational therapists would be able to assist patients to discover individual means by which this may be achieved.

\section{Implications for Psychologists and Counsellors}

Chronic pain isolates sufferers from those around them. Participants often preferred to retreat from social situations rather than risk rejection or spoiling social interactions. They felt vulnerable to criticism. This poses the threat that the person may be cut off from sources of support. The chronic nature of this type of pain generates a need for ongoing support. More needs to be done in terms of educating significant others about the nature of chronic pain and the need for empathetic understanding on an ongoing basis. Families need to be assisted to deal with the fact that chronic pain imposes changes in one's ability to fulfil social roles as expected and it seems that family counselling may facilitate such understanding.

\section{Strengths of the Present Study}

One of the strengths of the study was that participants were no longer seeking a cure for their pain. They had learnt various means of coping. Since participants had accepted their condition and were focusing on coping, they were able to provide valuable insights into the specific coping strategies adopted. Coping strategies are cognitions or behaviour intended to manage a specific stressor such as chronic pain. Examples of coping strategies which may be adopted include the use of coping self statements, diverting attention, ignoring sensations, re-interpreting pain sensations, increasing behavioural activity or praying and hoping. (Haythornthwaite et al 1998; Jensen and Karoly 1991). Previous research has been criticised for collapsing coping strategies into categories, 
such as active and passive strategies, which means that specific coping measures cannot be identified (Haythornwaite et al 1998).

Schmitz et al (1996) postulated that people orient their actions and strivings towards the attainment of personal goals. Individuals are proposed to evaluate their life situation with respect to progress towards these goals, or movements away from them. Chronic pain is associated with a perceived threat to goal attainment. This circumstance may lead to a discrepancy between an actual and desired state. Such discrepancies trigger coping processes to neutralise the threat or minimise loss. In this model, two modes of coping were distinguished, namely, assimilative coping and accommodative coping. Assimilative coping is characterised by active attempts to change the situation. Conversely, accommodative coping is directed towards a revision of goals in accordance with perceived deficits and losses.

Participants explained how they had redefined their goals in order to accommodate the changes imposed by pain, without giving up, emphasising the value of accommodative coping, confirming previous research (Schmitz et al 1996). It has been suggested that there is a gap between the expectations of health professionals and sufferers themselves with respect to coping with intractable pain (Large and Strong 1997). Passive coping strategies have been linked to psychological distress and depression (Snow-Turek et al 1996). Well-being and activity level have been shown to be related to patients' beliefs in personal control over pain and to the strategies they use to control pain. Haythornthwaite et al (1998) point out that ignoring pain is frequently thought to be an adaptive strategy, but, contrary to expectations, this strategy may lead sufferers to experience increased pain together with a sense of perceived loss of control over the pain. This is particularly noticeable when the pain is responsive to increased activity. Health professionals tend to favour active, offensive coping strategies. In the current study, participants revealed that both active and passive coping strategies are needed, confirming previous research that flexibility in the use of coping measures is valuable (Large and Strong 1997). This research provides a basis on which such misunderstandings can be overcome, "putting the claim that active coping strategies are superior to accommodative processes in perspective".

\section{Recommendations for Further Research}

There is a need to develop reliable criteria for assessing the outcome of physiotherapy (and other treatments) which take into account the patient's perspectives of improvement in quality of life and well-being.

Participants in this study indicated that chronic pain has stimulated psychological and spiritual growth. How can this process be facilitated?

Participants emphasised the importance of hope in coping with chronic pain. Where can such hope be found when faced with an incurable condition? The qualitative method employed in this research reveals the individuality and particularity of a person's coping responses. The experience of chronic pain may be translated into a spiritual struggle and the meaning thereof may be sought in the spiritual aspect of man which requires further investigation by methods which give access to this dimension.

\section{Closing Reflections on this Study}

Health professionals are faced with complex issues when managing patients with chronic pain. Talking to people with chronic pain about what their pain means to them seems to be invaluable in enabling them to accept their condition and to transcend it. Pain can reorganise one's life and change priorities and perspectives. Enabling sufferers to allow chronic pain to have a positive impact on themselves and their lives seems to be a vital need and an extraordinary challenge.

\section{REFERENCES}

Autton N 1986 Pain: an exploration. Essex. Darton, Longman and Todd Ltd.

Balint M 1990 The doctor, his patient and the illness. Kent: Pitman Medical.
Bardin L D 2002 Physiotherapy and Low Back Pain Part 1 Outcomes Research in the Quest for Evidence. South African Journal of Physiotherapy 58: 3 - 7

Barrell J J, Aanstoos C, Richards AC, Arons M 1987 Human science research methods. Journal of Humanistic Psychology 27: 424 457

Bishop GD 1994 Health psychology. Boston: Allyn and Bacon

Charman RA 1989 Pain theory and physiotherapy. Physiotherapy 75: $247-254$

Cleaver G and Pallourios H 1994 Diabetes mellitus: experiencing a chronic illness. South African Journal of Psychology 24: 175-183

Eales CJ 1999 The impact of chronic disease and disability on the elderly. South African Journal of Physiotherapy 55: 9-14

Eales CJ, Stewart AV and Noakes TD 2000Chronic illness and quality of life. South African Journal of Physiotherapy 56: 10 - 16

Fernandez E, Clark T S, Rudick-Davis D 1999 A framework for conceptualization and assessment of affective disturbance in pain. In AR. Block, EF Kremer and E Fernandez Eds, Handbook of pain syndromes, biopsychosocial perspectives pp 123-147. London: Lawrence Erlbaum Associates, Publishers

Giorgi A 1983 Concerning the possibility of phenomenological psychological research Journal of Phenomenological Psychology 14: $130-143$

Giorgi A 1992 Description versus interpretation: Competing alternative strategies for qualitative research. Journal of Phenomenological Psychology 23: 119 - 135

Giorgi A 1997 The theory, practice, and evaluation of the phenomenological method as a qualitative research procedure. Journal of Phenomenological Psychology 28: 235 - 260

Gregg C, Robertus J, Stone J 1989 The psychological aspects of chronic illness. Illinois: Charles C. Thomas Publisher

Hawthorn J, Redmond K 1998 Pain: causes and management. Oxford: Blackwell Science

Haythornthwaite J A, Menefee L A, Heinberg L J, Clark M R 1998 Pain coping strategies predict perceived control over pain. Pain 77: $33-39$

Hilbert RA 1984 The acultural dimensions of chronic pain; flawed reality construction and the problem of meaning. Social Problems 31: $365-378$ 
Illich I 1976. Limits to medicine: Medical Nemesis - The expropriation of health. London: Marion Boyars

Jabbur S J, Saade N E 1999 Pain (suppl 6): S87 - S92

Jensen M P, Karoly P 1991 Control beliefs, coping efforts, and adjustment to chronic pain. Journal of Consulting and Clinical Psychology 59: $431-438$

Kerns R D, Rosenberg R, Jacob M C 1993 Anger expression and chronic pain. Journal of Behavioural Medicine 17: 57 - 67

Kruger D 1979 An Introduction to Phenomenological Psychology. Cape Town Wetton Johannesburg Juta and Co

Large R, Strong J 1997 The personal constructs of coping with chronic low back pain: is coping a necessary evil? Pain 73: $245-252$ Linton S J 1987 Chronic pain: the case for prevention. Behavioural Research Therapy 25: $313-317$

Melzack R 1990 The tragedy of needless pain. Scientific America 262: 19 - 25

Melzack R and Wall PD 1982 The challenge of pain. New York: Basic Books

Menges L J 1984 Pain: Still an intriguing puzzle. Social Science and Medicine 19: 1257 - 1260
Osborn M, Smith J A1998 The personal experience of chronic benign lower back pain: An interpretative phenomenological analysis. British Journal of Health Psychology 3: 65-83

Papaikonomou M 1991 Views of medical practitioners and psychologists on the inadequacies of the biomedical model and the role of psychologists in its extension. South African Journal of Psychology 21: 97 - 102

Price B 1996 Illness careers: the chronic illness experience. Journal of Advanced Nursing 24: 275 - 279

Schmitz U, Saile H, Nilges P 1996 Coping with chronic pain: flexible goal adjustment as an interactive buffer against pain-related distress. Pain 67: 41 - 51

Seers K Friedli K 1996 The patients' experience of their non-malignant pain Journal of advanced nursing 24: 1160-1168

Snow-Turek AL, Norris MP and Tan, G 1996. Active and passive coping strategies in chronic pain patients. Pain 64: 455 - 462

Smith JA 1996 Beyond the divide between cognition and discourse: Using phenomenological analysis in health psychology. Psychology and Health 11: 261 - 171

Shantall H M 1996 A heuristic study of the meaning of suffering among holocaust survivors. Unpublished doctoral dissertation. Pretoria: Unisa

Shipton E A 1993 Pain, acute and chronic. Johannesburg Witwatersrand University Press

Stiles W B 1993 Quality control in qualitative research. Clinical Psychology Review 13: 593-618.

Toombs S K 1992 The meaning of illness. Dordrecht/Boston/London: Kluwer Academic Publishers

Wade 2000 The Meaning of Chronic Pain. Unpublished Master's Dissertation.. Pretoria: Unisa

Waddell G 1991 Low back disability, a syndrome of Western civilization. Neurosurgery Clinics of North America 2:719- 738

Walker J Holloway I Sofaer B 1999 In the system: the lived experience of chronic back pain from the perspectives of those seeking help from pain clinics. Pain 80: 621 - 628

Walker M Akinsanya JA Davis BD and Marcer D 1990 The nursing management of elderly patients with pain in the community: study and recommendations. Journal of Advanced Nursing 15: 1154 - 1161

\section{Discover the secrets of the United Kingdom!}

\section{We are recruiting Physiotherapists, Speech and Language, Occupational Therapists, Dieticians, Radiographers and Pharmacists for cllents in the UK.} $+1$

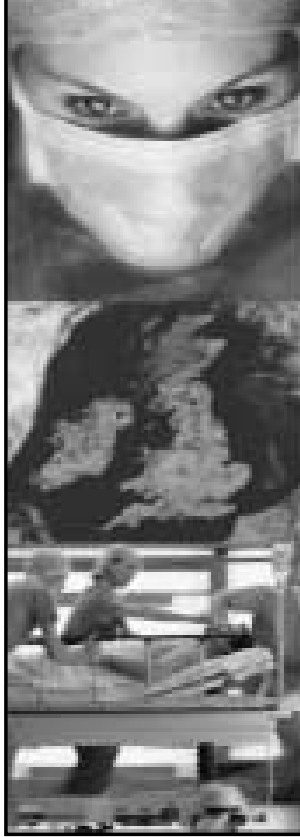

- Salary starting from $£ 18,375$ - $£ 26,055$ p.a depending on experience

- Accommodation, bank account \& PRI number arranged

- Orientation, meet and greet at the airport

- Paid annual leave and public helldays

O'Grady Peyton will assist you in obtaining HPC registration and a work permit. Our client team will provide on going support throughout your contract!

If you have formal qualifications in any of the above areas, at least 12 months experience post graduate and wish to join a dynamic organisation, plesse contact:

\section{Sonja Strydom:}

sonjastremweb.co.za

Renske Kotman:

renskekemweb.co.za

Tel: (012)347-9267

Fax: (012)347-5214

WE WILL SUPPORT YOU EVERY STEP OF THE WAYI

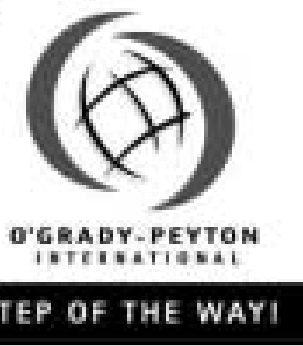

All correspondence to the editor

must be addressed to:

Prof CJ Eales -

Editor SASP Journal, School of

Therapeutic Sciences, Faculty of Health Sciences,

7 York Road,

Parktown 2193

E-mail:

ealescj@therapy.wits.ac.za

garstanglm@therapy.wits.ac.za 